\title{
Some Aspects on Well Log Interpretation of Lithological Analysis of Shaly Sand*
}

\author{
by Toshinobu Itoh** and Seiichi Hirakawa***
}

\begin{abstract}
Summary: Geophysical well log interpretation methods have able not only to calculate the porosity and the water saturation of the formation but also to perform the lithological analysis of formation materials. The methods of lithological analysis adopted at routine works in well logging are all indirect method which is based on the material balance equations composed with geophysical well log data and physical characteristics of the formation materials. But it is fact that many problems exist on these log interpretation methods, especially on the selection of reasonable value of physical parameter of formation materials for all cases of the formation.

Authors point out the problems of log interpretation methods used at routine works and discuss the usefulness of direct analysis methods of formation materials on the improvement of log interpretation.
\end{abstract}

\section{Introduction}

Geophysical well log data have been used for the geological classifications of the formation or the reference of seismographic interpretations of earth crust. The log interpretation methods in connection with the formation evaluation as seen at present day might have been founded by G. E. Archie ${ }^{1}$,2) who gave the quantitative relationships between the resistivity of clean formation and the water saturation in the pore space of formation.

At the early stage when well logging techniques were introduced into the oil well, the log interpretation has been performed with the combination of electrical $\log$ and micro $\log ^{3}$ ). The former measures formation resistivities and spontaneous potentioal in the hole by the method of so called normal and lateral electrode system, and the later measures the resistivity of mud flushed zone near close to the wall of bore-hole ${ }^{4), 5}$. But the measuring system of these logging methods are strongly affected by the condition of hole and formation. i.e., resistivity contrast between mud and formation, degree of mud invading to the formation, bed thickness of the formation,

* Received Jan. 11, 1973.

* Central Laboratory of Japan Petroleum Exploration Co.(Kichijoji-Kitamachi 3-7-20, Musashino, Tokyo, 180).

*** Department of Mineral Development Engineering, Faculty of Engineering, University of Tokyo (Hongo 7-3-1, Bunkyo-ku, Tokyo, 113) etc. Therefore, the reliability of log interpretation are strongly affected by the local conditions of oil field.

As the results of improvement of electronics technology in the past 20 years ago, many kinds of high quality logging tool have been put into the practical use. There are Inductuion-electrical Log, Latero Log, Micro-latero Log, Sonic Log, Density Log, Neutron Log, etc., 6) 9) and new log interpretation methods have been developed in accordance with the improvement of logging equipment. At present day, the geophysical well log interpretation methods can not only calculate formation porosity $(\phi)$ and water saturation $(\mathrm{Sw})$ but also perform the lithological analysis of formation materials ${ }^{10)}$ 13). The methods of lithological analysis adopted at routine works in well logging are all indirected methods which are based on the material balance equation composed with geophysical well log data and the physical characteristics of formation materials. On their methods, the most important factor is the selection of reasonable values of physical parameter of formation materials for all cases of formation, but it is fact that many problems exist on the selection of these parameters in practical cases.

\section{The Problems on the Log Interpretation of Lithological Analysis}

The analytical data of formation materials are very important factor on the well $\log$ interpreta- 
tion, especially on the calculation of porosity and water saturation of shaly formations ${ }^{14), 15}$. Fundamental formula of $\log$ interpretation for shaly formation used at the present day is as follows.

$$
\frac{1}{R_{\mathrm{t}}}=\frac{r_{\mathrm{sh}}}{R_{\mathrm{sh}}} S_{\mathrm{w}}+\frac{\phi^{2} S_{\mathrm{w}}{ }^{2}}{a R_{\mathrm{w}}}
$$

where, $R_{\mathrm{t}}=$ true resistivity of the formation

$R_{\mathrm{sh}}=$ resistivity of shalc contained in the formation

$V_{\mathrm{sh}}=$ shale concentrations of formation

$S_{\mathrm{w}}=$ water saturation in the pore space of formation

$\phi=$ porosity of formation

$\boldsymbol{R}_{\mathrm{w}}=$ resistivity of formation water

$a=$ compaction factor which takes $0.8 \sim$ 1.0 for normal case

$V_{\text {sh }}$ value can normally be obtained by the log interpretation of natural gamma-ray log or spontaneous potential $\log$, and also obtained by the method of material balance equation.

\section{1 $V_{\text {sh }}$ Caluculations by the Use of Natural Gamma-Ray Logging Data}

Radioactivities of the formation are due mainly to the radioisotopes of $\mathrm{K}-40$ and uranium minerals which are contained in the formation. Since the concentrations of $\mathbf{K}-\mathbf{4 0}$ in the shale is generally much higher than the one in the clean sand, the readings of the natural gamma-ray $\log$ at shaly formation indicate higher values than the one at clearn formation ${ }^{9)}$. Therefore, the following emprical equation has been introduced into practical uses by Schlumberger ${ }^{4}$.

$$
r_{\mathrm{sh}}=\frac{\rho_{\mathrm{b}} G R-B_{0}}{\rho_{\mathrm{sh}} G R_{\mathrm{sh}}-B_{0}}
$$

Where, $G R_{\mathrm{sh}}, \rho_{\mathrm{sh}}=$ radings of natural gammaray $\log$ and density $\log$ at the shale formation.

$G R, \rho_{\mathrm{b}}=$ readings of natural gammaray $\log$ and density $\log$ at the formation of calculated point.

$B_{0}=$ back ground value which is given by $G R_{\text {sand }} \times \rho_{\text {sand }}$ on the clean sand.

This equation can only be applied to the case where the sorts and the concentrations of radioisotope contained in the shale of shaly formation is coincided with the one of the shale formation where $G R_{\mathrm{sh}}, \rho_{\mathrm{sb}}$ are taken. But, in practical case, many abnormal phenomena will be seen. The reasons of abnormality which is appeared on natural gamma-ray $\log$ are as follows.

(a) The concentration of $\mathrm{K}-40$ in the shale differs with their chemical compositions ${ }^{16)}$.

(b) Some kinds of tuff or volcanic rock seen at oil reservoirs in Japan have high concentrations of uranium mineral, and show the high natural gamma-ray intensities.

\subsection{Caluculations by the Use of SP Logging Data}

It is well known that the spontaneous potential (SP) which is appeared at the permeable formation is due mainly to the activity (mobility) difference of the ion contained in the formation water and mud filtrate water. Since the mobility of ion in the formation is strongly disturbed by the shale if it is contained in the formation, SP at shaly sand (PSP) decreases in comparison with the one in clean sand (SSP) ${ }^{14}$ ). Therefore, the reduction rate of this $\mathrm{SP}$ will have some relationships with shale concentrations of the formation, and the following empirical equation has been introduced into the practical use.

$$
V_{\mathrm{sh}}=1-\alpha=\frac{\mathrm{SSP}-\mathrm{PSP}}{\mathrm{SSP}}
$$

where, $\alpha=$ PSP/SSP, SP reduction factor.

$\mathrm{SSP}=$ static SP on the clean sand.

PSP $=$ pscudo static SP on the shaly sand.

This equation is not founded by the theoretical experiments but introduced by the empirical results. Therefore, the reliability of this method is strongly affected by local conditions of the formation.

\subsection{Example of $V_{\text {sh }}$ Given by the Natural Gamma-Ray Log and SP Log}

(a) Abnormal high natural gamma-ray intensity on the sand formation.

At Fig. 1, formations of the depth of $2,132.1 \mathrm{~m}$, $2,138.0 \sim 2,141.0 \mathrm{~m}$ show the high natural gammaray intensities. Although the gamma-ray level of these formations is as high as the one on shaly formations, the log interpretation by the use of induction-electrical $\log$, sonic $\log$, density $\log$ and neutron $\log$ indicates that these formations will not be composed with the shale of $100 \%$ but composed with the hard rock having the high resistivity. Therefore, the high readings of the natural gamma-ray log on these formations will be due to the high concentrations of uranium minerals. The another examples of such high natural gamma-ray intensity on the sand can 


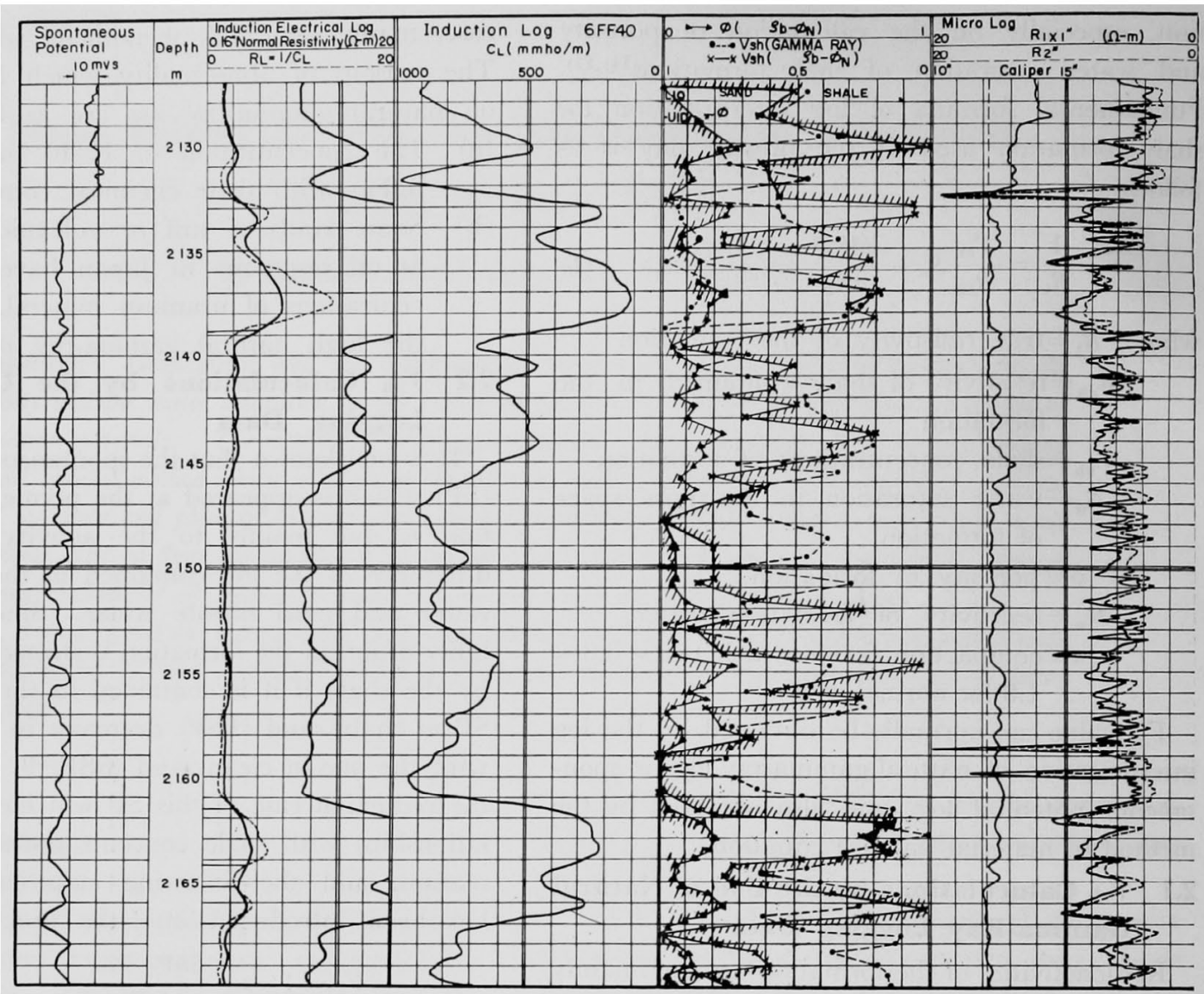

Fig. 1 Examples of $V_{\text {sh }}, \phi$ Calculated

be seen at Fig. 2 on the depth of 837.5 840.0 $\mathrm{m}$ and at Fig. 3 on the depth of 2,773.2 2,776.2 $\mathrm{m}$ and $2,798.0 \sim 2,804.0 \mathrm{~m}$.

(b) The difference of radioactive characteristics of the shale.

At Fig. 2, shale formations at the depth of $825.0 \mathrm{~m}, 840.5 \sim 842.5 \mathrm{~m}$ and $843.6 \sim 845.0 \mathrm{~m}$ have nearly same electical characteristics but have different gamma-ray intensities. This can be understood that the difference of natural gammaray intensity is mainly caused by the difference of chemical compositions of the shale. At the example of Fig. 3, the physical characteristics of shale formation might probably be changed at the depth of $2,765.0 \mathrm{~m}$ because the bulk density, resistivity and natural gamma-ray intensity of the upper section differ from the ones of the lower section.

(c) Co-relation between $\left[V_{\text {sh }}\right.$ given by the natural gamma-ray $\log$ and the one given by the SP log.

At the macroscopic view of 10 meters unit of the depth, $V_{\text {sh }}$ curves given by the natural gammaray $\log$ ( $V_{\mathrm{sh}}$-Gamma-ray) and by the SP $\log$ $\left(V_{\mathrm{sh}}-\mathrm{SP}\right)$ have nearly same tendency of shale contents of formation, but considerable deviations are seen at the microscopic view of one meter as shown in Fig. 2. It is natural that such deviation will exist because any quantitative relationship is not existed between both methods.

\section{4 $V_{\text {sh }}$ Calculations by the Use of Material Balance Equation}

As mentioned above, the shale contents of formation have not always been co-related with natural gamma-ray intensities of the formation or the reduction of spontaneous potential. Therefore, the more theoretical $V_{s \mathbf{s}}$ calculation methods which are based on the material balance equation composed with geophysical well log data and physical characteristics of formation materials have been proposed ${ }^{11) \sim 18}$.

On the water bearing formation, following material balance equations can be formed with the physical parameter of formation matericals and density $\log$, neutron $\log$ and sonic $\log$ data individually.

$$
\begin{aligned}
& \rho_{\mathrm{b}}=\rho_{\mathrm{f}} \phi+V_{\mathrm{sh}} \rho_{\mathrm{sh}}+\left(1-\phi-V_{\mathrm{sh}}\right) \rho_{\mathrm{ma}} \\
& \phi_{\mathrm{n}}=\phi+V_{\mathrm{sh}} \phi_{\mathrm{sh}}+\left(1-\phi-V_{\mathrm{sh}}\right) \phi_{\mathrm{ma}} \\
& \Delta T=\Delta T_{\mathrm{f}} \phi+V_{\mathrm{sh}} \Delta T_{\mathrm{sh}}+\left(1-\phi-V_{\mathrm{sh}}\right) \Delta T_{\mathrm{ma}}
\end{aligned}
$$

where, $\quad \rho_{\mathrm{b}}=$ bulk density of formation given

Bulletin of The Japan Petroleum Insțitute 


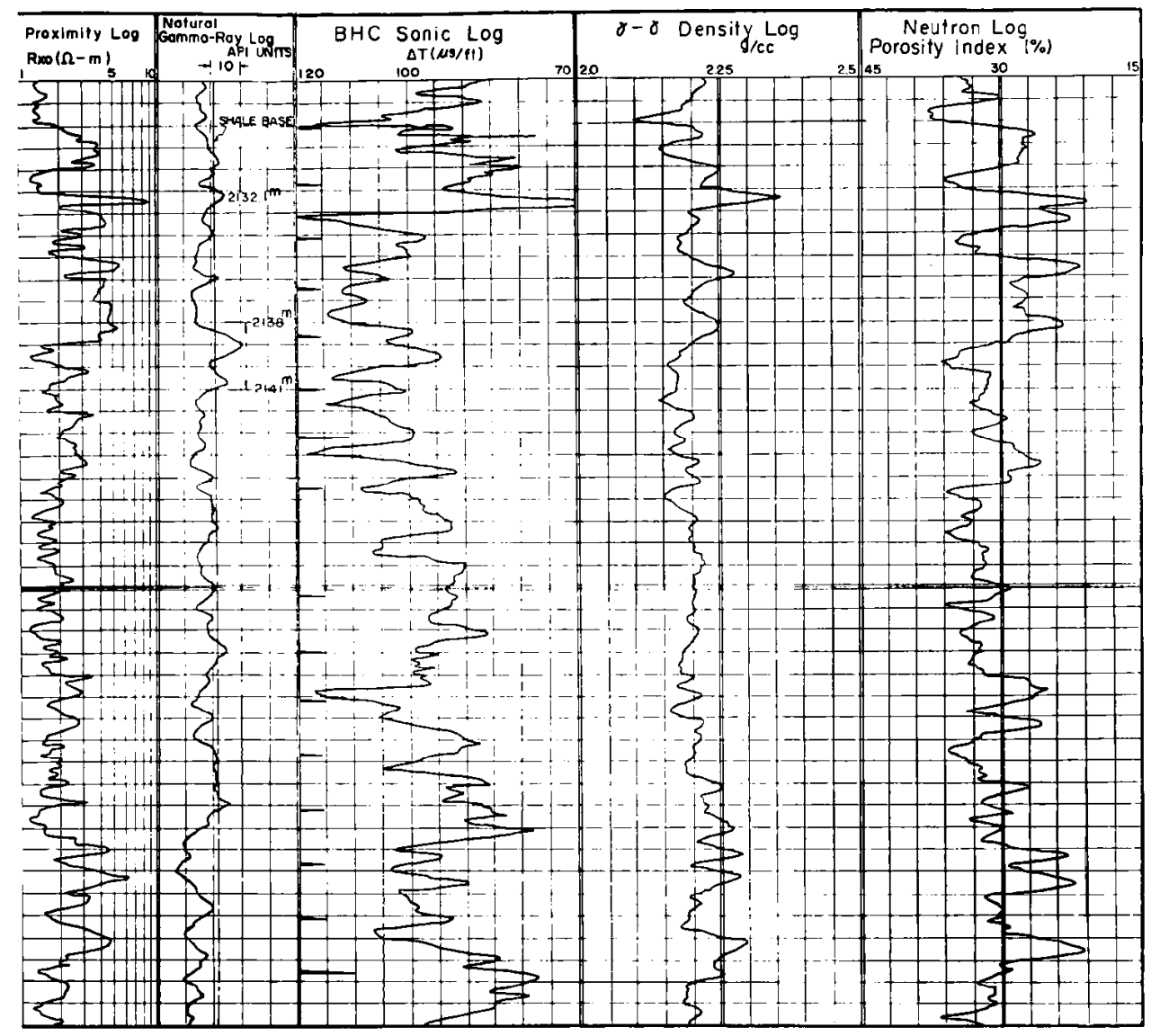

by Material Balance Equations

by the density log.

$\rho_{\mathrm{f}}, \rho_{\mathrm{sb}}, \rho_{\mathrm{ma}}=$ density of formation materials, i.e., formation fluids, shale and rock-matrix.

$\phi_{\mathrm{n}}=$ porosity index of fromation given by the neutron log.

$\phi_{\mathrm{sh}}, \dot{\phi}_{\mathrm{ma}}=$ neutron responses for shale and rock-matrix.

$J T=$ sonic transmission time $(\mu \mathrm{s} / \mathrm{ft})$ given by sonic $\log$.

$\Delta T_{\mathrm{sb}}, \Delta T_{\mathrm{ma}}=$ sonic transmission time of the formation materials.

$V_{\mathrm{sh}}$ values can be gained as the solution of simultaneous equation in combination with the two of these three equations. But it is easily understood that the value of $V_{\text {n }}$ given by this method is strongly affected with the physical parameter of formation materials, i.e., $\rho_{\mathrm{f}}, \rho_{\mathrm{ma}}$, $\rho_{\mathrm{sh}}, \phi_{\mathrm{sh}}, \phi_{\mathrm{ma}}, \Delta T_{\mathrm{sh}}, \Delta T_{\mathrm{ma}}$. Therefore, the selection of reasonable values on those parameters are very important to perform the reliable log interpretation. The reasonable value of these physical parameters will normally be decided by the results of core test of formation samples or the local experience of $\log$ interpretation empirically, but the values given by such methods does not always represent the physical characteristics of formation materials at the calculated point. The method proposed here is the one of check method of the reasonable values of $\rho_{\mathrm{ma}}, T_{\mathrm{ma}}$ and $V_{\mathrm{sh}}$ by the use of mathematical approaches, and details are as follows.

Since the responses of SNP (Side wall neutron porosity tool)*) for the rock-matrix are normally negligibly small in comparison with the one for water and shale $)^{4}\left(\phi_{\text {ma-sandstone }}=-0.035\right.$, $\phi_{\text {ma-11mestone }}=0$ and $\left.\phi_{\text {ma-dolomota }}=+0.035\right)$, the equation (4) can be rewritten as follows.

$$
\begin{aligned}
& \rho_{\mathrm{b}}=\rho_{\mathrm{r}} \phi+V_{\mathrm{sh}} \rho_{\mathrm{sh}}+\left(1-\phi-V_{\mathrm{sh}}\right) \rho_{\mathrm{ma}} \\
& \phi_{\mathrm{n}}=\phi+V_{\mathrm{sh}} \phi_{\mathrm{sh}} \\
& \left.1 T=\Delta T_{\mathrm{f}} \phi+V_{\mathrm{sh}} \Delta T_{\mathrm{sh}}+\left(1-\phi-V_{\mathrm{sh}}\right)\right\lrcorner T_{\mathrm{ma}}
\end{aligned}
$$

Then, following $V_{\mathrm{Bn}}$ will bc driven by the use of simultaneous equations composed with the pair of $\Delta T-\phi_{\mathrm{n}}, \rho_{\mathrm{b}}-.1 T$ and $\phi_{\mathrm{n}}-\rho_{\mathrm{b}}$ individually.

$$
V_{\mathrm{sh}\left(\Delta T-\phi_{\mathrm{n}}\right)}=\frac{1-\phi_{\mathrm{n}}}{1-\phi_{\mathrm{sh}}} \cdot \frac{\frac{\Delta T-\phi_{\mathrm{n}} \Delta T_{\mathrm{f}}}{1-\phi_{\mathrm{n}}}-\Delta T_{\mathrm{ma}}}{\frac{\Delta T_{\mathrm{sh}}-\phi_{\mathrm{sh}} \Delta T_{\mathrm{f}}}{1-\phi_{\mathrm{sh}}}-\Delta T_{\mathrm{ma}}}
$$

*) Side wall epithermal neutron porosity tool; Schlumberger name.

Volume 15, No. 2, November 1973 


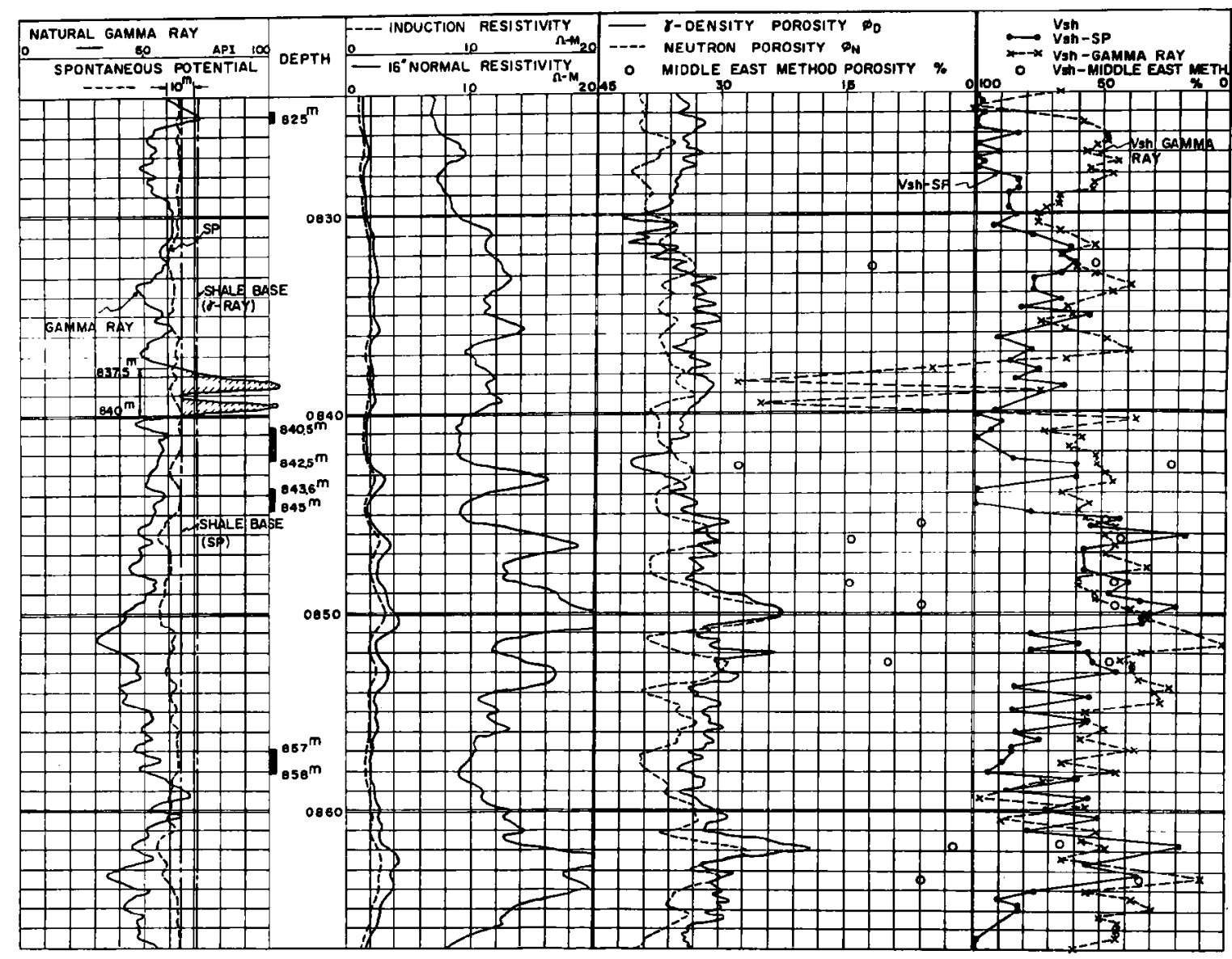

Fig. 2 Examples of Abnormality of Natural Gamma-Ray Log

Table la Average Shale Parameters

\begin{tabular}{c|c|c|c|c|c|c}
\hline Depth $(\mathrm{m})$ & $\Delta T(\mu \mathrm{s} / \mathrm{ft})$ & $\rho_{\mathrm{b}}\left(\mathrm{g} / \mathrm{cm}^{\mathrm{a}}\right)$ & $\phi_{n}$ & $A$ & $C$ & $K$ \\
\hline $2,127.5$ & 95 & 2.21 & 0.335 & 47.6466 & 2.8195 & 0.9896 \\
2,147 & 94 & 2.20 & 0.340 & 45.0606 & 2.8182 & 0.9821 \\
$2,1492,151$ & 93 & 2.20 & 0.320 & 47.8235 & 2.7647 & 1.0119 \\
2,153 & 98 & 2.19 & 0.330 & 53.1791 & 2.7761 & 0.9970 \\
$2,159 \sim 2,161$ & 89.5 & 2.235 & 0.315 & 43.7445 & 2.8029 & 1.0193 \\
\hline A.S.P. & 93.5 & 2.207 & 0.328 & 47.4905 & 2.7963 & 1.0000 \\
\hline$B=\frac{\Delta T_{\text {sh }}-\phi_{\text {sh }} \Delta T_{\mathrm{f}}}{1-\phi_{\text {sh }}}=47.4821$ & $D=\frac{\rho_{\text {sh }}-\phi_{\text {sh }} \rho_{\mathrm{f}}}{1-\phi_{\text {sh }}}=2.7961$ & & &
\end{tabular}

$$
\begin{aligned}
= & K \frac{A-\Delta T_{\mathrm{ma}}}{B-\Delta T_{\mathrm{ma}}} \\
V_{\mathrm{sh}\left(\rho_{\mathrm{b}}-\phi_{\mathrm{b}}\right)}= & \frac{1-\phi_{\mathrm{a}}}{1-\phi_{\mathrm{sh}}} \cdot \frac{\frac{\rho_{\mathrm{b}}-\phi_{\mathrm{n}} \rho_{\mathrm{f}}}{1-\phi_{\mathrm{n}}}-\rho_{\mathrm{ma}}}{\frac{\rho_{\mathrm{sh}}-\phi_{\mathrm{sh}} \rho_{\mathrm{f}}}{1-\phi_{\mathrm{sh}}}-\rho_{\mathrm{ma}}} \\
= & K \frac{C-\rho_{\mathrm{ma}}}{D-\rho_{\mathrm{ma}}} \\
\left.V_{\mathrm{sh}(\rho \mathrm{b}}-\Delta T\right)= & \frac{\frac{\rho_{\mathrm{b}}-\rho_{\mathrm{ma}}}{\rho_{\mathrm{f}}-\rho_{\mathrm{ma}}}-\frac{\Delta T-\Delta T_{\mathrm{ma}}}{\Delta T_{\mathrm{f}}-\Delta T_{\mathrm{ma}}}}{\frac{\rho_{\mathrm{sh}}-\rho_{\mathrm{ma}}}{\rho_{\mathrm{q}}-\rho_{\mathrm{ma}}}-\frac{\Delta T_{\mathrm{sh}}-\Delta T_{\mathrm{ma}}}{\Delta T_{\mathrm{f}}-\Delta T_{\mathrm{ma}}}}
\end{aligned}
$$

Where,

$$
\begin{aligned}
& A=\frac{\Delta T-\phi_{\mathrm{n}} \Delta T_{\mathrm{f}}}{1-\phi_{\mathrm{n}}}, \quad B=\frac{\Delta T_{\mathrm{sh}}-\phi_{\mathrm{sh}} \Delta T_{\mathrm{f}}}{1-\phi_{\mathrm{sh}}}, \\
& C=\frac{\rho_{\mathrm{b}}-\phi_{\mathrm{n}} \rho_{\mathrm{f}}}{1-\phi_{\mathrm{n}}}, \quad D=\frac{\rho_{\mathrm{sh}}-\phi_{\mathrm{sh}} \rho_{\mathrm{f}}}{1-\phi_{\mathrm{sh}}}, \\
& K=\frac{1-\phi_{\mathrm{n}}}{1-\phi_{\mathrm{sh}}}
\end{aligned}
$$

When the physical parameter of formation materials is correctly chosen, the macroscopic $V_{\text {sh }\left(\Delta T-\phi_{\mathrm{n}}\right)}$ and $V_{\mathrm{sh}}\left(\rho_{\mathrm{b}}-\phi_{\mathrm{n}}\right)$ which are driven as an average value of numerous calculation points distributed during over ten meters of the depth will be coincided with each other. Therefore, the reasonable value of $\Delta T_{\mathrm{ma}}$ and $\rho_{\mathrm{ma}}$ can be 
Table 1b $V_{\mathrm{sh}}, \phi$ Calculation

\begin{tabular}{|c|c|c|c|c|c|c|c|c|c|c|}
\hline \multirow{2}{*}{$\operatorname{Depth}(\mathrm{m})$} & \multirow{2}{*}{$\underset{(\mu \mathrm{s} / \mathrm{ft})}{\Delta T}$} & \multirow{2}{*}{$\begin{array}{c}\rho_{\mathrm{b}} \\
\left(\mathrm{g} / \mathrm{cm}^{3}\right)\end{array}$} & \multirow{2}{*}{$\phi_{\mathrm{n}}$} & \multirow{2}{*}{$A$} & \multirow{2}{*}{$C$} & \multirow{2}{*}{$K$} & \multicolumn{2}{|c|}{$\rho_{\mathrm{ma}}=2.65 \mathrm{~g} / \mathrm{cm}^{\mathrm{s}}$} & \multirow{2}{*}{$\begin{array}{c}\Delta T_{\mathrm{ma}}= \\
55.5 \mu \mathrm{s} / \mathrm{ft} \\
V_{\mathrm{sh}}\left(\phi_{\mathrm{n}}-\Delta T\right)\end{array}$} & \multirow{2}{*}{$\begin{array}{c}\Delta T_{\mathrm{ma}}= \\
70.5 \mu \mathrm{s} / \mathrm{ft} \\
V_{\mathrm{sh}}\left(\phi_{\mathrm{n}}-\Delta T\right) \\
\end{array}$} \\
\hline & & & & & & & $V_{\mathrm{sh}}\left(\phi_{\mathbf{n}}-\rho_{\mathrm{b}}\right)$ & $\left|\phi\left(\phi_{\mathrm{n}}-\rho_{\mathrm{b}}\right)\right|$ & & \\
\hline $\begin{array}{c}2,127.5 \\
2,130.2 \\
2,131 \\
2,134 \sim 2,135 \\
2,137 \\
2,147 \\
2,149 \sim 2,151 \\
2,153 \\
2,159 \sim 2,161 \\
2,162.2 \\
2,162.9 \\
2,165 \\
2,166.2\end{array}$ & $\begin{array}{c}95 \\
95 \\
87 \\
100 \\
110 \\
94 \\
93 \\
98 \\
89.5 \\
95 \\
103.5 \\
100 \\
103.5\end{array}$ & $\begin{array}{l}2.210 \\
2.150 \\
2.245 \\
2.180 \\
2.200 \\
2.200 \\
2.200 \\
2.190 \\
2.235 \\
2.285 \\
2.195 \\
2.190 \\
2.295\end{array}$ & \begin{tabular}{|l|}
0.335 \\
0.280 \\
0.285 \\
0.330 \\
0.280 \\
0.340 \\
0.320 \\
0.330 \\
0.315 \\
0.230 \\
0.290 \\
0.315 \\
0.215
\end{tabular} & $\begin{array}{l}47.6466 \\
58.4444 \\
46.3427 \\
56.1642 \\
80.0345 \\
45.0606 \\
47.8235 \\
53.1791 \\
43.7445 \\
66.9221 \\
68.5775 \\
59.0730 \\
80.0828\end{array}$ & \begin{tabular}{|l|}
2.8195 \\
2.5972 \\
2.7413 \\
2.7612 \\
2.6667 \\
2.8182 \\
2.7647 \\
2.7761 \\
2.8029 \\
2.6688 \\
2.6831 \\
2.7372 \\
2.6497
\end{tabular} & $\begin{array}{l}0.9896 \\
1.0714 \\
1.0640 \\
0.9970 \\
1.0714 \\
0.9821 \\
1.0119 \\
0.9970 \\
1.0193 \\
1.1458 \\
1.0565 \\
1.0193 \\
1.1682\end{array}$ & $\begin{array}{r}1.1481 \\
-0.3872 \\
0.6649 \\
0.7588 \\
0.1225 \\
1.1307 \\
0.7944 \\
0.8605 \\
1.0667 \\
0.1474 \\
0.2394 \\
0.6084 \\
-0.0024\end{array}$ & $\begin{array}{l}0 \\
0.4070 \\
0.0669 \\
0.0811 \\
0.2398 \\
0 \\
0.0594 \\
0.0478 \\
0 \\
0.1817 \\
0.2115 \\
0.1154 \\
0.2158\end{array}$ & $\begin{array}{r}0.9693 \\
-0.3934 \\
1.2152 \\
-0.0826 \\
-3.3014 \\
1.2787 \\
0.9688 \\
0.2889 \\
1.4945 \\
-1.6323 \\
-1.7232 \\
-0.4542 \\
-3.5817\end{array}$ & $\begin{array}{r}0.9825 \\
0.5611 \\
1.1167 \\
0.6209 \\
-0.4438 \\
1.0854 \\
0.9969 \\
0.7502 \\
1.1848 \\
0.1781 \\
0.0882 \\
0.5060 \\
-0.4863\end{array}$ \\
\hline Average & 97.2 & 2.213 & 0.297 & |57.9304 & 2.7267 & 1.0457. & 0.5502 & 0.1813 & -0.3810 & 0.5493 \\
\hline
\end{tabular}

Average $V_{\mathrm{sh}}\left(\rho_{\mathrm{b}}-\phi_{\mathrm{a}}, \rho_{\mathrm{ma}}=2.65\right)=\frac{C-\rho_{\mathrm{ma}}}{D-\rho_{\mathrm{ma}}} \cdot K=0.5455$

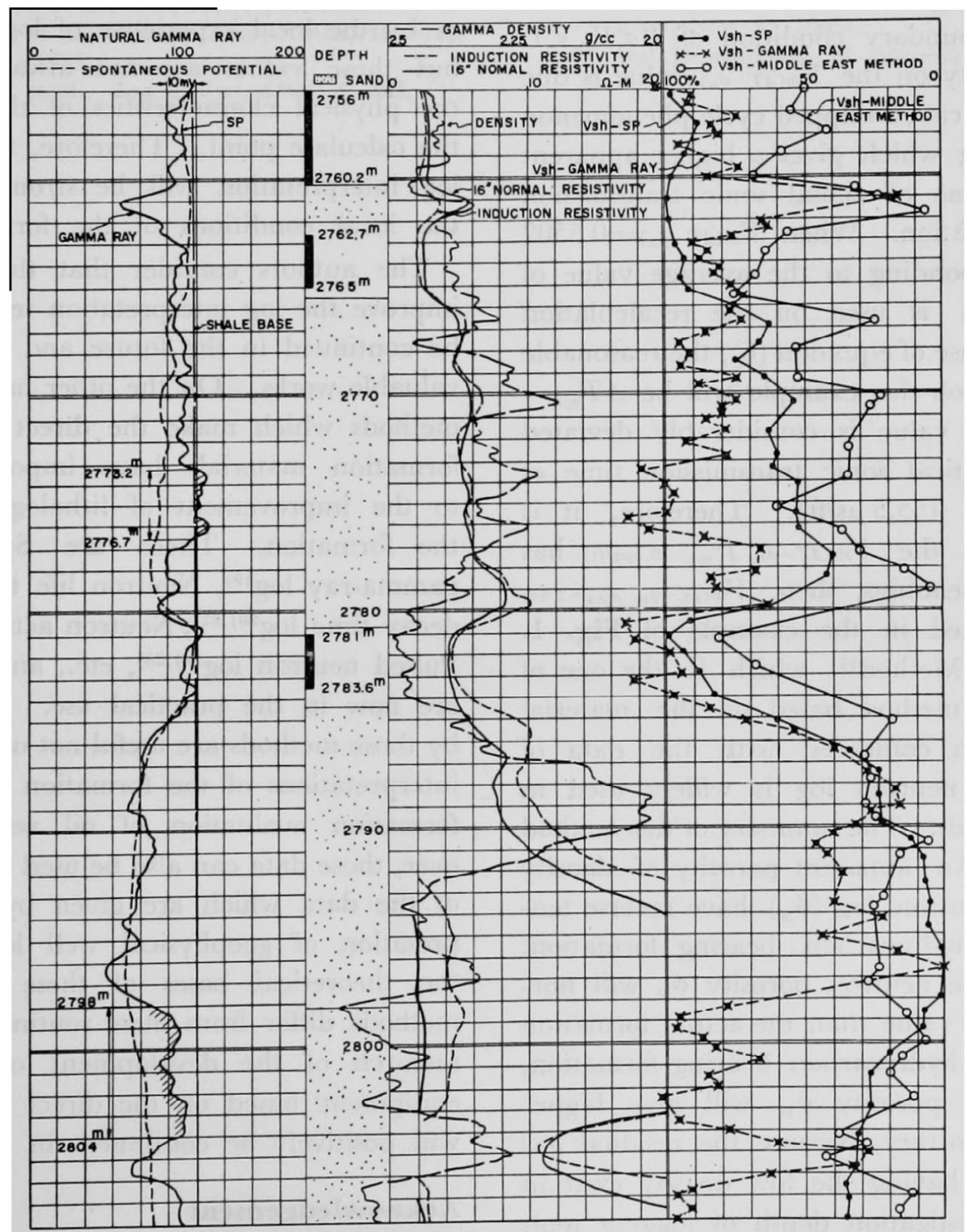

Fig. 3 Corelation between Natural Gamma-Ray $I_{s h}$ and SP $V_{\text {sh }}$

checked by the correlation between those values. Table $1 \mathrm{a}$ is the list of shale parameter on the example of Fig. 1. The values of $B$ and $D$ driven by the equations mentioned above with the value of shale parameters $\Delta T_{\mathrm{sh}}=93.5 \mu \mathrm{s} / \mathrm{ft}$, $\rho_{\mathrm{sh}}=2.207 \mathrm{~g} / \mathrm{cm}^{3}, \phi_{\mathrm{sh}}=0.328$ given in the table,

Volume 15, No. 2, November 1973 
i.e.,

$$
\begin{aligned}
& B=\frac{\Delta T_{\mathrm{sh}}-\phi_{\mathrm{sh}}-1 T_{\mathrm{f}}}{1-\phi_{\mathrm{sh}}}=47.4821, \\
& \mathrm{D}=\frac{\rho_{\mathrm{sh}}-\phi_{\mathrm{sh}} \rho_{\mathrm{f}}}{1-\phi_{\mathrm{sh}}}=2.7961
\end{aligned}
$$

are considerably coincided with the average values of $A$ and $C$ respectively, moreover, an average value of $K$ in these formations is unity. Therefore, these parameters might represent the shale characteristics on this example.

Table 1b shows $V_{\text {sh }}$ values driven by the use of equations $(6)$ and (7) with the shale parameters shown above. In this table, the average value of $V_{\text {sh }\left(J T-\phi_{\mathrm{n}}\right)}$ with a rock parameter of $\rfloor T_{\mathrm{ma}}=$ $55.5 \mu \mathrm{s} / \mathrm{ft}$ (an average sonic transmission time in the sand-stone $e^{4}$ ) gives -0.3810 , and this is not satisfying the boundary condition of $0<V_{\mathrm{sh}}<1$. This abnormality on the $\gamma_{\mathrm{sh}}\left(\Delta T-\phi_{\mathrm{n}}\right)$ value is due mainly to the so called skipped cycle phenomenon on the sonic $\log$ which gives a higher apparent $J T$ than the one of actual sonic transmission time of the formation. When $V_{\mathrm{sh}\left(\Delta T-\phi_{0}\right)}=0.5502$ which is corresponding to the average value of $V_{\mathrm{sh}}\left(\rho_{\mathrm{b}}-\phi_{\mathrm{a}}, \rho_{\mathrm{ma}}=2.65\right)$ is used on the recalculation of $\Delta T_{\operatorname{ma}}$ by the use of equation (6), the reasonable values of $\Delta T_{\mathrm{ma}}$ on this example will be $\Delta T_{\mathrm{ma}}=$ $70.5 \mu \mathrm{s} / \mathrm{ft}$. This value is considerably deviated from the theoretical sonic transmission time of the sand-stone $(55.5 \mu \mathrm{s} / \mathrm{ft})$. Therefore, it is understood that the $V_{\mathrm{sh}}\left(J T-\phi_{\mathrm{n}}, \Delta T_{\mathrm{ma}}=70.5 \mu \mathrm{s} / \mathrm{ft}\right)$ has no theoretical meanings, then, $\Gamma_{\mathrm{sh}\left(\rho_{\mathrm{b}}-\phi_{\mathrm{n}}, \rho_{\mathrm{ma}}=2.65\right)}$ values are plotted in the example of Fig. 1.

Middle East Method ${ }^{17}$ ) which is the one of $V_{\mathrm{sh}}$ caluclation method based on the material balance equation composed with the data of density $\log$ and neutron $\log$ is widely used in Japanease oil fields. The summary of this method is as follows. An apparent porosity of density $\log \left(\phi_{\mathrm{D}}\right)$ and neutron $\log \left(\phi_{\mathrm{N}}\right)$ have reverse tendency on the hydrocarbon bearing formation. For instance, the neutron porosity $\phi_{\mathrm{N}}$ will normally give lower value than the actual formation porosity on the hydrocarbon bearing formation, but the density porosity $\phi_{\mathrm{D}}$ will give higher value on the contrary, because the residual gas or hydrocarbon having the low density exist in the area of investigation depth of logging tools (the investigation depth of neutron log and density $\log$ are normally around from $10 \mathrm{~cm}$ to 15 $\mathrm{cm}$ from the wall of bore-hole ${ }^{8), 24)}$. Therefore, hydrocarbon correction can be performed with the combination of $\phi_{\mathrm{D}}$ and $\phi_{\mathrm{N}}$. Since many kinds of report concerning the process of hydrocarbon correction of this method have been published ${ }^{4), 17), 18)}$, the details of this method will not be described in this paper, but the results of the calculation are shown in Fig. 3 marked $0-0$.

\section{Considerations}

Although $V_{\text {sh }}$ calculation methods based on the material balance equation are much theoretical method in comparison with the one based on the natural gamma-ray log or SP $\log$, it is fact that many problems exist on these methods as described above. The value of physical parameters of the formation is normally given by the results of core analysis of formation samples or by the local experience of log interpretation, but those values are not always represent of the physical characteristics of the formation at the calculate point. Therefore, the reliability of $\log$ interpretation will be strongly affected by the local conditions of the formation.

The authors consider that the efforts which improve the $\log$ interpretation techniques should be continued in the future and such efforts are valuable works. On the other hand, the logging methods which make the direct analysis of the formation materials have important meanings to the improvement of lithological analysis of the formation. There are Spectral natural gamma-ray $\log ^{19)}$, Neutron life time or Neutron decay time $\log ^{20), 21)}$, Neutron activation $\log ^{22,, 23)}$, Pulsed neutron $\log ^{24), 25)}$, etc., and some of them are now in the practical use. The data given by those methods are useful not only to geological interpretations of the formation but also to the formation evaluation of oil reservoirs. Moreover, those data can also be used as the references of the data which are given by the log interpretation of geophysical well loggings because the theoretical bases of these direct analysis methods differ from these routine method. The research of the development of high quality equipment based on the direct analysis method will positively be continued in the future.

\section{Acknowledgement}

Authors wish to express their appreciations to Mr. H. Iwamoto and Mr. M. Ukai of Japan Petroleum Exploration Co. who gave us the valuable instructions and kind advices. 


\section{References}

1) Archie, G. E., J. Petrol. Tech., ALME, 5, (1), T. P. 1442 (1942).

2) Archie, G. E., Bull. AAPG, 31, 350 (1947).

3) Pirson, S. L., Handbook of Woll Log Analysis, (1963) Prentice Hall Co.

t) Schlumberger, Log Interpretation Principles, (1969).

5) Dresser Atlas, Log Review 1, (1971).

6) Geophysics, Geophysics, XXV, (4), (1960).

7) Schopper, J. R., Log Analyst, SPWLA, X, (4), (1969).

8) Tittman, J. et al., The Physical Foundation of Formation Density Logging, Geophysics, Nuclear Geophysics Conference, Poland, Oct. 1, (1962).

9) AIME, Well Logging, Petroleum Transactions Reprint Series, (1959).

10) Schmidt, A. W., Lng Analyst, SPIVLA, XIII, (1) (1972).

11) Savre, II. C., J. Petrol. Tech., AIME, 26, (9), (1963).

12) Poupon, A. et al., ibid., 34, (8), (1971).

13) Roper, W. A. et al., ibid., 32, (7), (1969).

14) Poupon, A. et al., Petrol. Trans., AIME, 16, (10), T. P. 3800 (1953).

15) Poupon, A. et al., Log Analyst, SPWLA, XI, (4),
(1971).

16). Overton, H. L., Log Analysl, SPIVLA, XII, (3), (1971).

17) Schlumberger, W'cll Evaluation Conference Middle East, Schlumberger Text Book (1967).

18) Gaymard, et al., Log Analvst, SPWLA, IX, (5), (1969).

19) Brannon, H. R. Jr., Petrol. Trans., AIME, 207, T. P. 4208 (1956).

20) Clavier, C. et al., J. Petrol. Tech., AIME, 33, (6), (1971).

21) Youmans, A. H. et al., Log Analyst, SPWLA, XU, (2), (1971).

22) Keys, W. S. et al., Log Analyst, $S P W L A, \mathbf{X},(6)$, (1969).

23) Caldwell, R. L. et al., Log Analyst, SPWLA, IX, (3), (1968).

24) Itoh, T., Pulsed Neutron Well Logging Techniques, 8th World Petroleum Congress, Moscow, Jun. 12 , (1971).

25) Czubek, J. A., Neutron Methods in Geophysics, Symp. Use of Nuclear Techniques in the Prospecting Aires, Nov. 5, (1968).

and Development of Mineral Resources, Buenos 